\title{
Neuro-Anatomical Variation of Lateral Cord of Brachial Plexus
}

\author{
Dr. A. Vasanthi, Dr. D. Asha Latha, Dr. T. Surekha, Dr. M. Srihari babu, \\ Dr.Deena Usha. \\ Department of Anatomy, Andhra Medical College, Visakhapatnam.
}

\begin{abstract}
During the educational gross anatomy dissections of the infra-clavicular part of brachial plexus of a 50-year-old male cadaver in our department of anatomy, Andhra medical college, Visakhapatnam, we have encountered a neuroanatomical variation. The lateral cord of brachial plexus and its branches, had a different configuration. On the right side, the median nerve received very few fibres from the lateral cord of brachial plexus during its formation. On both sides the musculo-cutaneous nerve has given an accessory branch which again joined the main trunk of the median nerve.This variation has clinical importance in median nerve lesions and its distinctive diagnosis. Lesions of the median nerve, if lesion was proximal to this accessory branches, muscles and cutaneous innervations related to this branch were normal.
\end{abstract}

Key Words: Medial root of median nerve, Lateral root of median nerve, Accessory branch of musculocutaneous nerve.

\section{Introduction:}

We have observed an accessory branch of the musculocutaneous nerve. This variation has clinical importance in median nerve lesions and its distinctive diagnosis. The coracobrachialis muscle is usually supplied by the musculocutaneous nerve. Its innervation pattern exhibits a considerable variation. The change in the innervation of the coracobrachialis muscle is reported to be closely correlated with the change of course of the musculocutaneous nerve $[2,3]$. The musculocutaneous nerve usually arises from the lateral cord of the brachial plexus, pierces and innervates the coracobrachialis muscle [2, 4]. However, the course and branching anomalies of the musculocutaneous nerve and its relation to the coracobrachialis muscle have been documented in the literature by Koizumi [2], Buch [5], Flatow et al. [6], and Le Minor [7]. On the other hand, the distribution,course and branching of the musculocutaneous nerve is important from the clinical point of view, especially in compression neuropathies due to vigorous activity and stretch injuries seen in various surgical interventions.

\section{Case Report:}

Variations were noted during the dissection for under-graduate students.

The infraclavicular part of brachial plexus was dissected and the following findings were noted.

Right side: (Image 1) On the right side, the median nerve received very few fibres from the lateral cord of brachial plexus during its formation. At a distance of $12 \mathrm{cms}$ from the tip of coracoid process the musculocutaneous nerve gave an accessory branch which has joined the main trunk of median nerve at a distance of $17 \mathrm{cms}$ from the tip of coracoid process. Giving its accessory branch and the nerve to the biceps brachii and brachialis muscle, the musculocutaneus nerve coursed normally as a lateral cutaneous nerve of forearm.

Left side:(Image 2) On the left side the median nerve formation is normal. At a distance of $10.5 \mathrm{cms}$ from the tip of coracoid process the musculo- cutaneous nerve gave an accessory branch which has joined the main trunk of median nerve at a distance of $13.5 \mathrm{cms}$ from the tip of coracoid process. Giving its accessory branch and the nerve to the biceps brachii and brachialis muscle, the musculocutaneus nerve coursed normally as a lateral cutaneous nerve of forearm. 


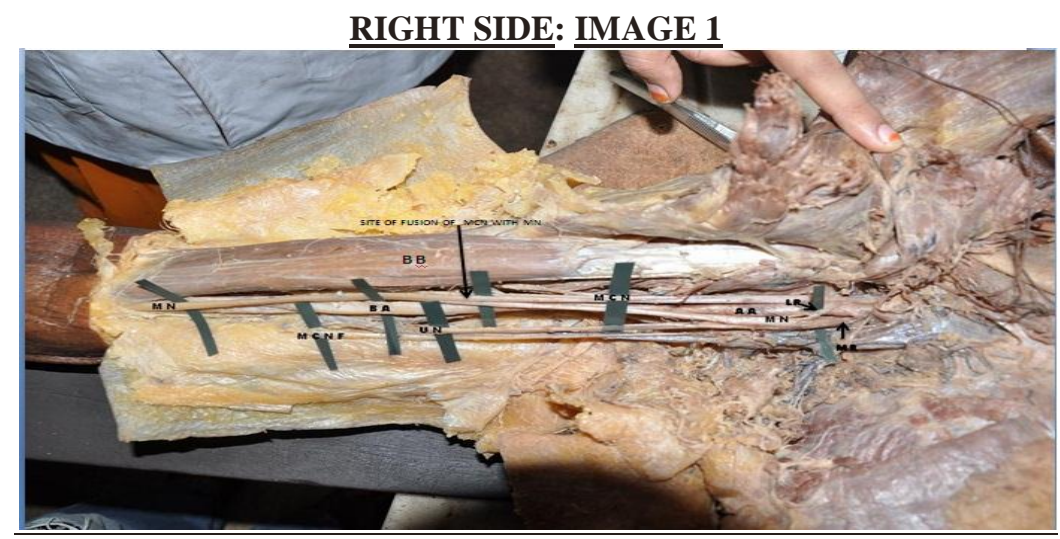

1)MR: Medial root of median nerve 2)LR: Lateral root of median nerve 3)MN: Median nerve 4)AA: Axillary artery 5)MCN: Musculo-cutaneous nerve 6)BB :Biceps brachii 7)UN: Ulnar nerve 8)BA: Brachial artery 9)MCNF: Medial cutaneous nerve of fore-arm

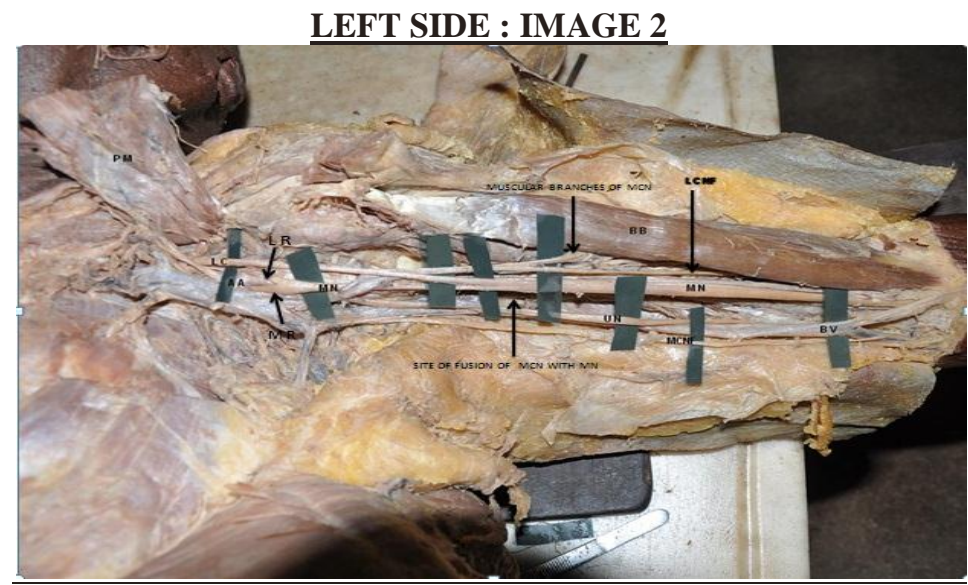

1)PM: Pectoralis minor 2)LC: Lateral cord 3 )AA: Axillary artery 4)MR: Medial root of median nerve 5)LR: Lateral root of median nerve 6)MN: Median nerve 7)MCN: Musculo-cutaneous nerve 7)BB :Biceps brachii 8)UN: Ulnar nerve 9)LCN: Lateral cutaneous nerve of forearm. 10)BV: Basilic vein.

\section{Discussion:}

The musculocutaneous nerve usually arises from the lateral cord of the brachial plexus (C5, C6 and C7), pierces the coracobrachialis muscles and then passes downward between the biceps and the brachialis muscle. It appears at the lateral margin of the biceps tendon and runs down the lateral aspect of the forearm as the lateral cutaneous nerve of the forearm after piercing the fascia just above the elbow. It sometimes shows wide distribution to the skin. Appleton [11] showed a case of complete absence of the cutaneous branch of the radial nerve, to the hand, and replacement by the musculocutaneous nerve. The distribution and the course and the branching of the musculocutaneous nerve is important from the clinical viewpoint. Linell [12] advised that for clinical investigation and the surgical treatment of peripheral nerve injury, a more precise knowledge than that found in classical anatomical texts was necessary, because the musculocutaneous nerve sometimes runs a different course and supplies some branches to the median nerve, a communicating branch. According to Hollinshead [13], this is usually interpreted as meaning that fibers that should have run through the lateral root of the median nerve failed to do so, but entered the musculocutaneous and rejoined the median nerve. Iwamoto [14] analyzed the root of communicating branch with the median nerve, and described the communicating branch, consisting of fibers arising from C5 and C6. There have been many reports of the occurrence of a communication between the musculocutaneous nerve and the median nerve [3, 5, 14-17]. Communication between the musculocutaneous and the median nerve was considered as a remnant from the phylogenetic or comparative anatomical view point. The median nerve has two roots from the lateral and medial cords. The medial root of the median nerve crosses the axillary artery at an oblique angle to join the lateral root, thus forming the median nerve. The nerve to coracobrachialis muscle lies close to the axillary artery but then usually pierces the coracobrachialis muscle and passes laterally and obliquely to lie between the biceps brachii and brachialis. 


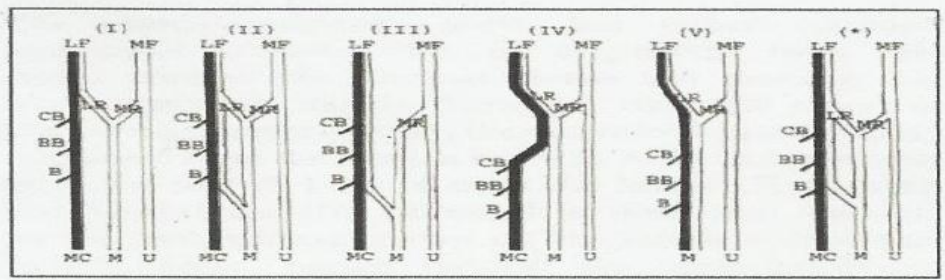

Figwre Shoving illustrations of five types of the musculocutaneous and the median nerves $(I-V)$ and our case ( $)$. ( I.F: Lateral cord; $M / F$; medial cord; $M C$ : musculocutaneons nerve; $M$ : median nerve; $U$ : ulnar nerve; CB: coracobrachialis muscle; BB: biceps brachii muscle; B: brachialis muscle; $L . R$ : Lateral root of median nerve; $M$ MR: medial root of median nerve)

Le Minor(7) has described the variations in 5 types:

Type I: there are no connecting fibers between the musculocutaneous and median nerve as described in classic textbooks $[18,19]$. The musculocutaneous nerve pierces the coracobrachialis muscle and innervates the coracobrachialis, the biceps brachii and brachialis muscle.

Type II: although some fibers of the medial root of the median nerve unite with the lateral root of the median nerve and form the main trunk of median nerve, remaining medial root fibers run in the musculocutaneous nerve leaving it after a distance to join the main trunk of median nerve.

Type III: the lateral root of the median nerve from the lateral cord runs in the musculocutaneous nerve and leaves it after a distance to join the main trunk of median nerve.

Type IV: the fibers of the musculocutaneous nerve unite with the lateral root of the median nerve. After some distance, the musculocutaneous nerve arise from the median nerve.

Type V: the musculocutaneous nerve is absent. The fibers of the musculocutaneous nerve run within the median nerve along its course. In this type the musculocutaneous nerve does not pierces the coracobrachialis muscle.

The musculocutaneous nerve has rather constant anatomical features, that is, originating from the lateral cord of the brachial plexus and piercing the coracobrachialis muscle. However, Buch [5] reported that, in his cadaveric study, the musculocutaneous nerve originated from the median nerve in 3-6\% and from the posterior cord in 1-5\% of cases. Le Minor [7], Spinner and Winkelman [20] observed in their case that the lateral cord, without giving off the lateral root of the median nerve, passed through the coracobrachialis muscle and innervated the coracobrachialis, biceps brachii and brachialis muscles. On the other hand, the musculocutaneous nerve does not pierce the coracobrachialis muscle in some instances (according to Buch, up to $(14 \%)$ or even might be absent in rare cases because to musculocutaneous nerve joins the median nerve [2]. In our case, the musculocutaneous nerve pierced the coracobrachialis muscle.

\section{Conclusion:}

Communications between musculo-cutaneous nerve and median nerve may be considerable significance to neurologists and orthopaedicians in treating patients of nerve entrapment syndromes of the upper limb. The variant course of the musculocutaneous nerve should be kept in mind as a possible way of treatment in recurrent compression neuropathies. This variation has clinical importance in median nerve lesions and its distinctive diagnosis. In median nerve lesions proximal to the accessory branches, motor and sensory innervation remains normal.

\section{References:}

[1] Kerr AT. The brachial plexus of nerves in man, the variations in its formation and branches. Am. J. Anat. 1918; 23: 285-395.

[2] Koizumi M. A morphological study on the coracobrachialis muscle. Kaibogaku Zasshi. 1989; 64: 18-35.

[3] Watanabe M, Takatsuji K, Sakamoto N, Morita Y, Ito H. Two cases of fusion of the musculocutaneous and median nerves. Kaibogaki Zasshi. 1985; 60: 1-7.

[4] Kosugi K, Shibata S, Yamashita H. Supernumerary head of biceps brachii and branching pattern of themusculocutaneous nerve in Japanese. Surg. Radiol. Anat. 1992; 14: 175-185.

[5] Buch C. On the variation in the method of innervation of the biceps muscle of the arm with special reference to branches from the musculocutaneous nerve and the median nerve. Anat. Anz. 1964; 114: 131-140.

[6] Flatow EL, Bigliani LU, April EW. An anatomic study of the musculocutaneous nerve and its relationship to the coracoid process. Clin. Orthop. Relat. Res. 1989; 244: 166-171.

[7] Le Minor JM. A rare variation of the median and musculocutaneous nerves in man. Arch. Anat. Histol. Embryol. 1990; 73: 33-42.

[8] Braddom RL, Wolfe C. Musculocutaneous nerve injury after heavy exercise. Arch. Phys. Med. Rehabil. 1978; 59: 290-293. 
[9] Caspi I, Ezra E, Nerubay J, Horoszovski H. Musculocutaneous nerve injury after corocoid process transfer for clavicle instability. Acta Orthop. Scand. 1987; 58: 294-295.

[10] Pecina M, Bojanic I. Musculocutaneous nerve entrapment in the upper arm. Int. Orthop. 1993; 17: $232-234$.

[11] Appleton AB. A case of abnormal distribution of the musculocutaneous nerve, with complete absence of the ramus cutaneous nervus radialis. J. Anat. Physiol. 1912; 46: 89-94.

[12] Linell EA. The distribution of nerves in the upper limb, with reference to variabilities and their clinical significance. J. Anat. 1921; 55: 79-112.

[13] Hollinshead WH. Anatomy for surgeons. The back and limbs. 3rd Ed., Harper \& Row, Philadelphia,1982.

[14] Iwamoto S, Kimura K, Takahashi Y, Konishi M. Some aspects of the communicating branch between the musculocutaneous and median nerves in man. Okajimas Folia Anat. Jpn. 1990; 67: 47-52.

[15] Fujita T. Complete fusion of the musculocutaneous and median nerve in a human arm, with some anomalies of the biceps brachii muscle. Kaibogaku Zasshi. 1957; 32: 257-262.

[16] Monden M. The communication between the median nerve. Juzen Med. 1942; 47: 2045-2055.

[17] Serisawa M, Hagura N, Eto M. On the third head of the biceps brachii muscle and its relation to the lateral cutaneous nerve of the forearm. Dokkyo J. Med. Sci. 1978; 5: 303-312.

[18] Arinci K, Elhan A. Anatomi. Gunes Kitapevi, Ankara. 1997; p. 210-220.

[19] Williams PL, Bannister LH, Berry MM, Collins P, Dyson M, Dussek JE, Ferguson MWJ. Gray's anatomy 38th Ed., Churchill Livingstone, Edinburgh. 1995; pp: 842, 1269, 1924.

[20] Spinner M, Winkelman MA. Variant branch of median nerve. Bull. Hosp. Joint Dis. 1973; 34: 161-196. 